\title{
La solidaridad interterritorial como valor educativo del Derecho financiero $y$ tributario
}

Solidarity between territories as an educational value of financial and tax law

\section{Roberto Ignacio Fernández López}

Catedrático de Derecho financiero y tributario

Universidade de Vigo

E-mail: rfernandez@uvigo.es

\begin{abstract}
Resumen: La solidaridad es un valor ético-jurídico que potencia y garantiza la pacífica convivencia entre los pueblos y entes territoriales que conforman una determinada comunidad político-administrativa. Pero, además, es un destacado elemento pedagógico e instructivo que debe impregnar el aprendizaje de las disciplinas jurídicas y, muy especialmente, del Derecho financiero y tributario. Por ello, este trabajo tiene por objeto analizar el principio de solidaridad en su vertiente interterritorial, abordándolo como uno de los valores educativos relevantes que el Derecho financiero y tributario está llamado a cultivar y desarrollar entre el alumnado de las Facultades de Derecho. A tal fin se estudia su proyección y aplicación por la Unión Europea y por el ordenamiento financiero español.
\end{abstract}

Palabras clave: Solidaridad interterritorial, Derecho financiero y tributario, valores educativos. 


\begin{abstract}
Solidarity is an ethical-legal value that strengthens and guarantees peaceful coexistence between the peoples and territorial entities that make up a given politicaladministrative community. But it is also an important pedagogical and instructive element that should permeate the learning of legal disciplines and, in particular, financial and tax law. For this reason, the aim of this paper is to analyse the principle of solidarity in its territorial perspective, addressing it as one of the relevant educational values that financial and tax law should develop among students in Law Faculties. To this end, its projection and application by the European Union and the Spanish legal system is studied.
\end{abstract}

Keywords: Solidarity between territories, Financial and tax law, educational values.

Sumario: 1. Planteamiento introductorio. 2. Los instrumentos jurídico-financieros impulsados por la Unión Europea para contribuir al equilibrio económico entre los Estados miembros y sus regiones. 3. La solidaridad interterritorial y su proyección en la actividad financiera del Estado autonómico. 3.1. El anclaje constitucional de la solidaridad como principio jurídico y valor de convivencia. 3.2. Los instrumentos previstos en el ordenamiento estatal para hacer posible la solidaridad interterritorial. 3.3. Las distorsiones creadas en el sistema de financiación de los regímenes forales. 3.4. El contraste con la solidaridad federal en Alemania. 4. Bibliografía.

\title{
1. Planteamiento introductorio
}

Como es sabido, la Declaración Universal de Derechos Humanos (1948) proclama como uno de los objetivos de la educación, entre otros, el "fortalecimiento del respeto a los derechos humanos y a las libertades fundamentales" (art. 26.2). En la misma línea, el art. 27.2 de la Constitución Española de 1978 (CE) declara que "la educación tendrá por objeto el pleno desarrollo de la personalidad humana en el respeto a los principios democráticos de convivencia y a los derechos y libertades fundamentales". A la vista de lo anterior, se aprecia que la Carta Magna incorpora un interesante añadido a la norma auspiciada por las Naciones Unidas al referirse, además, a "los principios democráticos de convivencia". No cabe duda que estos últimos son los que figuran enumerados en su art. 1, esto es, la libertad, la justicia, la igualdad y el pluralismo político, los cuales a su vez se proyectan sobre el modelo de Estado autonómico cuyas señas de identidad son el 
derecho a la autonomía de las nacionalidades y regiones que integran la Nación española, así como "la solidaridad entre todas ellas" (art. 2 CE).

La solidaridad es también uno de los grandes pilares sobre los que se asienta la Unión Europea (art. 2 TUE) ${ }^{147}$, al punto que esta última se compromete, por un lado, a fomentar la cohesión económica, social y territorial, junto con "la solidaridad entre los Estados miembros" (art. 3.3 TUE). Por otra parte, en sus relaciones con el resto del mundo, la UE pretende contribuir a "la solidaridad y el respeto mutuo entre los pueblos" (art. 3.5 TUE).

Pues bien, teniendo en cuenta la destacada posición que las normas citadas le otorgan a la solidaridad, al erigirse en uno de los pilares clave que coadyuvan a mantener un adecuado marco de convivencia entre los distintos países que conforman la Unión Europea y entre los diversos territorios o regiones que componen cada Estado miembro, consideramos oportuno en las líneas que siguen centrar nuestra atención en el principio de solidaridad en su vertiente interterritorial analizándolo, a los fines de este trabajo, como uno de los valores educativos relevantes que el Derecho financiero y tributario como disciplina académica- está llamado a desarrollar entre el alumnado de las Facultades de Derecho. Es decir, la solidaridad no sólo es un principio ético-jurídico de indudable aplicación práctica sino que, adicionalmente, es un valor pedagógico e instructivo que debe impregnar el aprendizaje de las disciplinas jurídicas y, muy especialmente, del Derecho financiero y tributario. Los futuros juristas deben conocer el alcance y la trascendencia de dicha máxima como mecanismo tendente a garantizar la justicia social y el reparto equitativo de riqueza entre los pueblos o territorios que se integran en un determinado nivel de gobierno, sea éste regional, estatal o supranacional.

El planteamiento anterior enlaza con los objetivos y metas de desarrollo sostenible de la Agenda 2030 de las Naciones Unidas, pues entre ellos figura la educación en valores por supuesto también en los niveles educativos superiores- y la educación como instrumento para fomentar una distribución justa de los recursos públicos. Es evidente además que la cooperación internacional, en el plano de la fiscalidad y del gasto público, mitiga las limitaciones de los países cuando estos por sí solos no son capaces de conseguir

\footnotetext{
147 Tratado de la Unión Europea, publicado en el DOUE núm. 83, de 30 de marzo de 2010 (DOUE-Z-201070002)
} 
esos objetivos marcados por la Agenda 2030 de Naciones Unidas (OWENS, LENNARD, ANDRÉS AUCEJO, 2020, 13).

En este estado de cosas, y como planteamiento general, los estudios universitarios del Grado en Derecho deben proporcionar al alumnado la "base" y el "fondo" de su formación jurídica (OLIVER ARAUJO, 2003, 27). La "base" aporta el saber o conocimiento y permite practicar el aprender. Suelen ser categorías dogmáticas abstractas, principios basilares e instituciones que actúan de pilares sobre los que se construye la ciencia jurídica. Ese contenido esencial proporciona solidez y consistencia en el proceso de aprendizaje del Derecho, por lo que nunca se verá afectado por posibles cambios normativos o por el concreto dato normativo aplicable en un momento dado. Se aprecia aquí una técnica inductiva dirigida a conseguir útiles formulaciones generales con validez temporal indefinida $y$, por tanto, sin verse sometidas a eventuales modificaciones del ordenamiento legal. En suma, se trata de valores jurídicos supremos que sustentan la convivencia colectiva y le permiten al Derecho desempeñar su función primordial, esto es, actuar como un sistema de organización social.

Pero este primer paso, aun siendo absolutamente necesario, resulta insuficiente para que un egresado afronte con mínimas garantías de éxito los innumerables retos profesionales que encontrará al concluir su etapa universitaria. Por eso es imprescindible que las Facultades de Derecho incidan además en el "fondo" del proceso de aprendizaje. Con esto último se fomenta el saber hacer y el saber estar, se generan y estimulan nuevas necesidades de aprendizaje (aprendizaje continuo), se incentiva el espíritu crítico para solventar con criterios de justicia las controversias jurídicas surgidas en la práctica profesional y, en definitiva, se aprende a aprender. Con ello se culmina o completa el análisis de la situación concreta y, siguiendo una mecánica deductiva, se proponen soluciones adaptadas al supuesto planteado.

A nuestro juicio, las dos fases descritas son perfectamente aplicables al alumnado de Derecho financiero y tributario cuando en su proceso de enseñanza-aprendizaje se abordan valores jurídicos esenciales en los que se asienta la convivencia cívica, como es el principio de solidaridad en su proyección interterritorial. Así las cosas, este último no solo es un principio básico informante de la actividad financiera pública en un Estado descentralizado como el español sino que, además, es una de los criterios éticos que debe 
propugnar el aprendizaje de las competencias propias de la citada disciplina académica en los centros universitarios. Las Facultades de Derecho en general, y el Derecho financiero en particular, no sólo deben formar profesionales con competencias técnicas suficientes para afrontar situaciones de conflicto o controversia, sino que además deben preparar ciudadanos con claros referentes éticos y morales, capaces de involucrarse en tareas dirigidas a alcanzar mayores cuotas de igualdad y bienestar social. Todo ello lo resume GONZÁLEZ-TREVIJANO (2006, 93-94) en lo que, a su juicio, son las cuatro funciones propias de la Universidad: a) Función cívica o de ciudadanía (educacional). b) Función de enseñanza integral (humanística). c) Función transformadora y promocional de la sociedad (sociológica). d) Función socializadora e igualitaria (equitativa).

Por último, como tendremos ocasión de comprobar, la solidaridad interterritorial, en un claro proceso de retroalimentación, también actúa de instrumento o palanca para conseguir un nivel mínimo en la prestación de los servicios públicos fundamentales, entre los cuales se encuentra la educación. En otras palabras, la educación y la enseñanza superior no sólo es una de las destacadas herramientas al servicio de la solidaridad sino que además esta última, desde una perspectiva estrictamente financiera, fomenta el acceso a la educación en igual de condiciones a todos los miembros de una colectividad humana.

\section{Los instrumentos jurídico-financieros impulsados por la Unión Europea para contribuir al equilibrio económico entre los Estados miembros y sus regiones}

Una de las ideas motrices que orienta la política presupuestaria y financiera de la Unión Europea es la cohesión económica, social y territorial entre los Estados miembros. Prueba de ello es que el TFUE dedica el Título XVIII de su Tercera Parte a esta concreta materia (arts.174 a 178) ${ }^{148}$. Conviene subrayar que esa convergencia pretendida por la UE se aleja de postulados territoriales de tipo estatal y, en cambio, presenta un marcado carácter regional.

De este modo, el principal objetivo de la UE es "reducir las diferencias entre los niveles de desarrollo de las diversas regiones y el retraso de las regiones menos favorecidas". Con tal meta, "se prestará especial atención a las zonas rurales, a las zonas afectadas por

148 Tratado de Funcionamiento de la Unión Europea, publicado -conjuntamente con el TUE- en el DOUE núm. 83, de 30 de marzo de 2010 (DOUE-Z-2010-70002). 
una transición industrial y a las regiones que padecen desventajas naturales o demográficas graves y permanentes como, por ejemplo, las regiones más septentrionales con una escasa densidad de población y las regiones insulares, transfronterizas y de montaña" (art. 174 TFUE).

Los principales programas que ha venido utilizando la UE para corregir esas diferencias entre distintas zonas o territorios de los Estados miembros han sido los fondos con finalidad estructural: Fondo Europeo de Orientación y de Garantía Agrícola, sección "Orientación" (FEOGA); Fondo Social Europeo (FSE); y Fondo Europeo de Desarrollo Regional (FEDER) ${ }^{149}$.

A los anteriores habría que añadir, por el sustancioso volumen presupuestario que representa, el Fondo de Cohesión, el cual ha sido creado para proporcionar una contribución financiera a dos proyectos estratégicos: el medio ambiente y las redes transeuropeas en materia de infraestructuras del transporte (art. 177 TFUE). Su principal finalidad ha sido reducir las disparidades socioeconómicas y promover el desarrollo sostenible de los Estados miembros.

Del Fondo de Cohesión, regulado inicialmente por el Reglamento (CE) 1164/94, de 16 de mayo de 1994, sólo han podido aprovecharse los Estados miembros que reuniesen dos requisitos: a) Poseer un producto interior bruto per cápita (PIB), calculado con arreglo a las paridades en poder de compra, inferior al $90 \%$ de la media comunitaria. b) Seguir un programa que les permitiese cumplir con las condiciones de convergencia económica (no incurrir en déficit excesivo). A partir del 1 de enero de 2000, fueron cuatro los Estados miembros que podían ser subvencionados en el marco del Fondo de Cohesión: España, Grecia, Portugal e Irlanda. La revisión intermedia de la Comisión realizada en 2003 consideró que Irlanda (cuyo PIB representaba el 101\% de la media) ya no cumplía los criterios para ser beneficiario de las subvenciones del Fondo de Cohesión a partir del 1 de enero de 2004. El 1 de mayo de 2004, fecha de la ampliación de la UE, todos los nuevos Estados miembros (Chipre, República Checa, Estonia, Hungría, Letonia, Lituania,

${ }^{149}$ Art. 175 TFUE. 
Malta, Polonia, Eslovaquia y Eslovenia) reunieron las condiciones para recibir la ayuda del Fondo de Cohesión. ${ }^{150}$

Posteriormente, en el período 2014-2020, el Fondo de Cohesión ha desplegado una importante ayuda financiera (63.400 millones $€$ ) destinada a los siguientes países: Bulgaria, Croacia, Chipre, Eslovaquia, Eslovenia, Estonia, Grecia, Hungría, Letonia, Lituania, Malta, Polonia, Portugal, República Checa y Rumanía. Las actividades subvencionables han sido de nuevo las dos inicialmente diseñadas para reducir las diferencias regionales: a) Redes transeuropeas de transporte, en particular los proyectos prioritarios de interés europeo identificados por la UE. b) Medio ambiente. En este segundo aspecto, el Fondo de Cohesión también ha dado impulso a los proyectos relacionados con la energía o el transporte, siempre que beneficiasen claramente al medio ambiente en términos de eficiencia energética, uso de energías renovables, desarrollo del transporte ferroviario, refuerzo de la intermodalidad, fortalecimiento del transporte público, etc. ${ }^{151}$

Desde luego, tampoco puede obviarse en este apartado el denominado Fondo de Solidaridad. Fue creado por el Reglamento (CE) 2012/2002, del Consejo, de 11 de noviembre de 2002, para intervenir en caso de catástrofes naturales graves y aportar la solidaridad europea a las regiones siniestradas de los Estados miembros. Su primera actuación fue contrarrestar las grandes inundaciones del verano de 2002 en Europa central. Desde entonces, se ha utilizado en 80 catástrofes de muy diversos tipos, como inundaciones, incendios forestales, terremotos, tormentas y sequías. ${ }^{152}$

Por lo demás, ante la necesidad de afrontar las nefastas consecuencias de la pandemia de la COVID-19, el 1 de abril de 2020 se amplió el ámbito de aplicación del Fondo de Solidaridad de la Unión Europea (FSUE) con el fin de dar cobertura a emergencias graves de salud pública. ${ }^{153}$ Así, ante una situación de pandemia vírica declarada oficialmente, la

\footnotetext{
150 Vid. https://ec.europa.eu/regional_policy/archive/funds/procf/cf_es.htm (Consultado el 20/01/2021). Tras la incorporación de nuevos Estados miembros en 2004, se aprobó el Reglamento (CE) 1084/2006 del Consejo, de 11 de julio de 2006, por el que se crea el Fondo de Cohesión y se deroga el Reglamento (CE) $1164 / 94$.

${ }^{151}$ Vid. https://ec.europa.eu/regional_policy/es/funding/cohesion-fund/ (Consultado el 20/01/2021).

152 Vid. https://ec.europa.eu/regional_policy/es/funding/solidarity-fund/\#2 (Consultado el 20/01/2021).

${ }^{153}$ La base jurídica de esa nueva finalidad del Fondo de Solidaridad se encuentra actualmente en el Reglamento (UE) 2020/461 del Parlamento Europeo y del Consejo, de 30 de marzo de 2020, por el que se modifica el Reglamento (CE) 2012/2002 del Consejo, a fin de proporcionar ayuda financiera a aquellos
} 
UE reconoce que debe colaborar en la movilización de recursos suficientes para atender necesidades inmediatas de los países miembros a corto y medio plazo. Se trata de complementar el esfuerzo de los Estados afectados cuando éstos no pueden afrontar por sí solos, con sus propios medios, los mecanismos de respuesta ante una crisis sociosanitaria de tal magnitud como la generada por la COVID-19. Jurídicamente, cuando un objetivo no es susceptible de alcanzarse de manera suficiente o adecuada por los Estados miembros, sino que, debido a las dimensiones y efectos de la acción, es posible lograrlo mejor a escala de la Unión, esta puede adoptar medidas de acuerdo con el principio de subsidiariedad establecido en el art. 5 del TUE. ${ }^{154}$

Por último, el Consejo Europeo de 21 de julio de 2020 ha sentado las bases para acometer un ambicioso programa de gasto que permita impulsar la convergencia, la cohesión, la resiliencia y la transformación en la Unión Europea. Así, se acordó fijar el futuro marco financiero plurianual (MFP) para 2021-2027 y se ha puesto en marcha un nuevo Instrumento Europeo de Recuperación («Next Generation EU») por valor de 750.000 millones de euros.

Este Instrumento Europeo de Recuperación, que implicará para España unos 140.000 millones de euros en forma de transferencias y préstamos para el periodo 2021-2026, se basa en tres pilares ${ }^{155}$ :

$1^{\circ}$. La adopción de mecanismos para apoyar los esfuerzos de los Estados miembros por recuperarse, reparar los daños y salir reforzados de la crisis sanitaria y económica derivada de la COVID-19.

\footnotetext{
Estados miembros y países cuya adhesión a la Unión esté en proceso de negociación, que se encuentren gravemente afectados por una emergencia grave de salud pública.

${ }^{154}$ Los costes cubiertos por el Fondo de Solidaridad para afrontar la crisis sanitaria provocada por la COVID-19 son los relacionados con todo tipo de asistencia a la población (medidas médicas, sanitarias y de protección civil) así como cualquier medida adoptada para contener la enfermedad, entre las que cabe citar las siguientes: A) Atención médica (incluidos los medicamentos, los equipos y productos sanitarios, la asistencia sanitaria y las infraestructuras de protección civil). B) Análisis de laboratorio. C) Equipos de protección individual (EPI). D) Asistencia especial a la población, en particular a grupos vulnerables (personas de edad avanzada o con problemas de salud, embarazadas, familias monoparentales, etc.). E) Ayudas especiales para mantener la operatividad del personal sanitario y de emergencias. F) Desarrollo de vacunas o medicamentos. G) Mejora de la evaluación y la gestión de riesgos. H) Desinfección de edificios e instalaciones. I) Controles sanitarios, incluidos los controles en frontera. J) Todos los costes adicionales de personal generados por la epidemia

155 Exposición de Motivos del Real Decreto-ley 36/2020, de 30 de diciembre, por el que se aprueban medidas urgentes para la modernización de la Administración Pública y para la ejecución del Plan de Recuperación, Transformación y Resiliencia.
} 
$2^{\circ}$. La adopción de medidas para impulsar la inversión privada y apoyar a las empresas en dificultades.

$3^{\circ}$. El refuerzo de los programas clave de la Unión Europea para extraer las enseñanzas de la crisis, hacer que el mercado único sea más fuerte y resiliente, así como acelerar la doble transición ecológica y digital.

En suma, resulta patente que la UE ha puesto en marcha en las últimas décadas variados instrumentos financieros para reducir las disparidades económicas entre los distintos países y regiones, así como para afrontar necesidades urgentes de gasto que los Estados miembros no son capaces de asumir con sus propios presupuestos. Ello es una muestra palmaria de la obligación jurídica impuesta por el TFUE de potenciar la solidaridad interregional y de acrecentar los niveles de desarrollo de las zonas más atrasadas o con menor índice de riqueza de la UE. Cuestión distinta es el grado de efectividad o los resultados que finalmente se hayan conseguido con dichos mecanismos de convergencia, extremo este último que se sustrae al objeto de este trabajo y del que se ocupan las ciencias económicas. Tampoco es misión del Derecho financiero analizar los aspectos jurídicos sustantivos o materiales del gasto público, en este caso del realizado por la UE a través de sus diferentes mecanismos de solidaridad entre países y regiones. No obstante, el Derecho presupuestario sí puede y debe incentivar entre el alumnado universitario el interés por conocer los procedimientos que rigen el ciclo presupuestario de la Unión, abordando el papel que desempeñan las distintas instituciones comunitarias en esta materia (Comisión, Parlamento, Consejo, Tribunal de Cuentas). Y para ello es posible tomar como ejemplo el recorrido que sigue cualquiera de los fondos, instrumentos o programas de gasto anteriormente descritos, desde su aprobación inicial, pasando por su ejecución presupuestaria, hasta llegar a su control o fiscalización por los órganos competentes de la UE. Con ello se consigue crear en los estudiantes universitarios el escenario adecuado para que vean la utilidad del gasto público de la UE como medio al servicio de la solidaridad interterritorial. 


\section{La solidaridad interterritorial y su proyección en la actividad financiera del estado autonómico}

\subsection{El anclaje constitucional de la solidaridad como principio jurídico y valor de convivencia}

Se ha señalado, con razón, que el Estado es un valor en sí mismo, "porque realiza funciones de solidaridad y de equilibrio entre los diferentes territorios españoles" (PÉREZ CALVO, 2005, 1196). Así, el Estado social de Derecho es quizá el mejor exponente de la solidaridad interpersonal ya que, de forma más intensa incluso que la Unión Europea, implementa instrumentos que la hacen efectiva, como por ejemplo a través del sistema público de la Seguridad Social, basado en un modelo de reparto generacional. Y también es posible concretar esa solidaridad colectiva a través del sistema tributario, por medio de estímulos fiscales. Un ejemplo de esto último lo constituye la deducción por donativos a entidades sin fines lucrativos prevista en el art. 68.3 de la LIRPF. ${ }^{156}$

En todo caso, el deber de contribuir al sostenimiento de los gastos públicos -impuesto por el art. 31.1 CE- se ampara, en último término, en la indispensable solidaridad colectiva, esto es, en una justa distribución de la carga tributaria entre los llamados a soportarla, pues de otro modo, como ya tuvo ocasión de señalar el TC, "lo que unos no paguen debiendo pagar, lo tendrán que pagar otros con más espíritu cívico o con menos posibilidades de defraudar" ${ }^{157}$.

Así pues, detrás de la obligación de abonar tributos con arreglo a las verdaderas manifestaciones de riqueza de cada individuo subyace la idea de la solidaridad entre los sujetos que conforman una determinada comunidad política. En otras palabras, cuando se abordan y analizan los principios de justicia tributaria en las aulas universitarias, es preciso dejar claro que el fundamento último del deber de contribuir con arreglo a la capacidad económica de cada sujeto se asienta en la solidaridad como elemento vertebrador y cohesionador de la sociedad. La vertiente del ingreso público, y más concretamente el tributo, cobra aquí todo su sentido, porque el alumnado de Derecho

\footnotetext{
${ }^{156}$ Ley 35/2006, de 28 de noviembre, del Impuesto sobre la Renta de las Personas Físicas.

${ }^{157}$ STC 110/1984, de 26 de noviembre (FJ $3^{\circ}$ ), y STC 76/1990, de 26 de abril (FJ $3^{\circ}$ ), entre otras.
} 
financiero logra comprender las ventajas y los enormes avances sociales que traen consigo los impuestos configurados y exigidos con arreglo a la riqueza real de los contribuyentes.

Pero además, como acabamos de señalar, la solidaridad interterritorial es otro de los mandatos constitucionales que está llamado a cumplir el Estado social y democrático de Derecho, porque es una herramienta que favorece la cohesión y la justicia social, entendiendo por esta última la necesidad de lograr un equilibrado reparto de los bienes colectivos, asegurando así la dignidad de todas las personas -cualquiera que sea el lugar en el que residan. Se aprecia en este sentido una proyección de la solidaridad que puede ir más allá de las puras transferencias financieras del Estado a las distintas partes de su territorio, en la medida en que también hay otras políticas públicas que, al margen de las asignaciones directas a otros niveles de gobierno con cargo a los Presupuestos Generales del Estado, hacen posible la justicia social y la vertebración del territorio, cuál sería -por citar un ejemplo- las inversiones directas del Estado en materia de infraestructuras hidráulicas o de transporte.

Desde esta perspectiva cobra especial interés la clasificación territorial del gasto público, prevista por el art. 37.2 d) de la $\mathrm{LGP}^{158}$, como información referida a los gastos de inversión que debe acompañar al proyecto de Ley de Presupuestos Generales del Estado. En esta misma línea cabe situar la Disposición Adicional $3^{\text {a }} .2$ de la LOFCA ${ }^{159}$, que establece la obligación del Ministerio de Hacienda de publicar anualmente la distribución provincial que presente el gasto público divisible. Todo ello permite valorar el grado de efectividad o cumplimiento del principio de solidaridad en su vertiente territorial.

Así las cosas, la solidaridad implica esencialmente un traslado de recursos hacia las personas o los territorios con un menor nivel de riqueza y desarrollo socioeconómico, en el bien entendido de que el objetivo razonable de dicho principio es la disminución de los desequilibrios y no la igualdad absoluta o la uniformidad (HERNÁNDEZ LAVADO, 2011, 471). La vertiente financiera es pues el contenido sustancial del principio de solidaridad, erigiéndose este último en uno de los ejes vertebradores sobre los que se asienta el Estado de las Autonomías, de tal suerte que condiciona poderosamente el

${ }^{158}$ Ley 47/2003, de 26 de noviembre, General Presupuestaria

${ }^{159}$ Ley Orgánica 8/1980, de 22 de septiembre, de Financiación de las Comunidades Autónomas 
sistema de financiación autonómica, bien limitando la autonomía de las CC.AA. o bien imponiéndoles a éstas obligaciones de resultado en sus respectivos territorios (DOMÍNGUEZ ZORRERO y SÁNCHEZ PINO, 2003, 157-158).

Pues bien, es lugar común en los estudios universitarios de Derecho ofrecerle al alumnado de Derecho financiero y tributario una formulación del principio de solidaridad que arranque de los preceptos constitucionales que lo consagran, como elemento transversal del ordenamiento financiero. Hay valores en la Carta Magna que implícitamente apelan a la solidaridad. Por ejemplo, cuando el art. 9.2 se refiere a la igualdad material que deben promover los poderes públicos, no cabe duda de que en el fondo late la idea de potenciar la redistribución de la renta y de la riqueza entre ciudadanos y partes del territorio español.

Lo mismo ocurre cuando establece el imperativo de que todos contribuyan al sostenimiento de los gastos públicos de acuerdo con su capacidad económica (art. 31.1 $\mathrm{CE}$ ), pues es evidente que este principio se ampara a su vez en la indispensable solidaridad de cada individuo como sujeto obligado a contribuir al levantamiento de las cargas públicas.

Pero, al margen de los preceptos constitucionales en los que tácitamente subyace la regla de la solidaridad, llama la atención las numerosas ocasiones en que la $\mathrm{CE}$ invoca expresamente este principio, lo que denota que no es una simple proclama carente de valor jurídico. Su título preliminar ya comienza apuntando que la autonomía reconocida a las nacionalidades y regiones debe ir acompañada de la "solidaridad entre todas ellas" (art. 2). Es cierto que esa autonomía político-administrativa requiere para su efectividad de una verdadera autonomía y suficiencia financiera, pero también esta última debe estar informada por "los principios de coordinación con la Hacienda estatal y de solidaridad entre todos los españoles” (art. 156.1). Además, el art. 158 señala dos posibles instrumentos para materializar la solidaridad: a) Una asignación a las Comunidades Autónomas, en función del volumen de los servicios y actividades estatales que hayan asumido, que garantice un nivel mínimo en la prestación de los servicios públicos fundamentales en todo el territorio español. b) Un Fondo de Compensación Interterritorial con destino a gastos de inversión. 
Y, en fin, el principal responsable de hacer efectiva la solidaridad es el propio Estado, pues a él corresponde velar por el establecimiento de un equilibrio económico, adecuado y justo entre las diversas partes del territorio español, atendiendo en particular a las circunstancias del hecho insular (art. 138.1). ${ }^{160}$

Con base en este conjunto de preceptos, la solidaridad interterritorial es un deber jurídico establecido por la Carta Magna, del que no puede sustraerse el Estado, el cual se ve compelido a procurar un desarrollo equilibrado y armónico de las distintas regiones que conforman el país. Como ha señalado LAGO MONTERO (2008, 3020), “el sujeto pasivo de la solidaridad interterritorial es el Estado, obligado a garantizarla a través de leyes de las Cortes Generales, de aplicación a todas las CC.AA.”. Evidentemente ello no obsta a que cada Comunidad Autónoma deba hacer lo propio dentro de su respectivo territorio, velando por aproximar el nivel de riqueza de las comarcas o zonas menos desarrolladas a las que presentan mejores índices de renta y bienestar ${ }^{161}$, pero lo que sí parece meridianamente claro es que el principal destinatario del mandato constitucional que afecta a la solidaridad interterritorial es el Estado, porque su concreción, como nos recuerda el art. $2 \mathrm{CE}$, debe materializarse sobre "las nacionalidades y regiones" que lo integran. En otras palabras, el poder constituyente no sólo ha instituido una obligación jurídica general a cargo del Estado sino que además le atribuye a éste un deber de resultado: corregir los desequilibrios económicos interterritoriales y redistribuir la riqueza entre las distintas Comunidades Autónomas con las herramientas que le proporciona el poder financiero conferido por la Carta Magna.

Precisamente, ese poder financiero originario o de rango constitucional le permite al Estado gozar de potestad legislativa y de competencia exclusiva sobre la Hacienda General (art. 149.1.14 a CE). Al amparo de esta atribución, y de lo dispuesto en el art. 157.3 CE, se aprobó en su momento la Ley Orgánica 8/1980, de 22 de septiembre, de Financiación de las Comunidades Autónomas (LOFCA). Desde la promulgación de esta última hasta la vigente Ley 22/2009, de 18 de diciembre, la financiación autonómica ha ido evolucionando de un modelo de transferencias del presupuesto estatal a las

\footnotetext{
${ }^{160}$ Al margen de lo anterior, la Constitución tampoco se olvida del plano interpersonal o colectivo de la solidaridad. En efecto, su art. 45.2 obliga a los poderes públicos a que, con base "en la indispensable solidaridad colectiva", velen por la utilización racional de todos los recursos naturales, con el fin de proteger y mejorar la calidad de la vida, y defender y restaurar el medioambiente.

${ }^{161}$ Vid. en este sentido las SSTC $179 / 1985\left(\mathrm{FJ} \mathrm{3} 3^{\circ}\right), 63 / 1986\left(\mathrm{FJ} 11^{\circ}\right)$ y 250/1988 (FJ $\left.4^{\circ}\right)$.
} 
Comunidades Autónomas de régimen común a un sistema en el que estas deben corresponsabilizarse junto al Estado del ejercicio de competencias en materia de ingresos y gastos públicos [art. 2.1 d) LOFCA].

No cabe duda que el tipo de financiación autonómica que se implemente tiene notorias repercusiones en la concreción efectiva del principio de solidaridad, por lo que resulta útil conocer en qué medida el marco jurídico regulador de la primera incide sobre el segundo.

Más concretamente, uno de los aspectos clave en este punto es determinar si solo la legislación estatal, singularmente la LOFCA y la Ley 22/2009, o también los Estatutos de Autonomía pueden desarrollar en el plano normativo el principio constitucional de solidaridad. A este respecto, conviene traer a colación la doctrina del Tribunal Constitucional sobre los efectos que despliega la solidaridad en el marco de las relaciones financieras entre el Estado y las Comunidades Autónomas, que podemos sintetizar como sigue:

- La solidaridad actúa como "un factor de equilibrio entre la autonomía de las nacionalidades o regiones y la indisoluble unidad de la Nación española (art. 2)" (STC 135/1992, de 5 de octubre - FJ $7^{\circ}$ ). Además, con base en el art. 156.1 CE, la solidaridad limita la autonomía financiera de las Comunidades Autónomas y, por derivación, su potestad tributaria (STC 49/1995, de 16 de febrero - FJ $4^{\circ}$ ).

- El art. $138.1 \mathrm{CE}^{162}$ “(...) no puede ser reducido al carácter de un precepto programático, o tan siquiera al de elemento interpretativo de las normas competenciales. Es, por el contrario, un precepto con peso y significado propios, que debe ser interpretado, eso sí, en coherencia con las normas competenciales que resultan de la Constitución y los Estatutos" (STC 146/1992, de 16 de octubre $\left.-\mathrm{FJ} 1^{\circ}\right)$.

- Sobre el sentido del art. 138.2 CE, cuando este dispone que "las diferencias entre los Estatutos de las distintas Comunidades Autónomas no podrán implicar, en

\footnotetext{
${ }^{162}$ Recordemos que, a tenor de dicho precepto, "el Estado garantiza la realización efectiva del principio de solidaridad consagrado en el artículo 2 de la Constitución, velando por el establecimiento de un equilibrio económico, adecuado y justo entre las diversas partes del territorio español, y atendiendo en particular a las circunstancias del hecho insular"
} 
ningún caso, privilegios económicos o sociales”, el Tribunal Constitucional considera lo siguiente: el principio de solidaridad requiere que "las Comunidades Autónomas en el ejercicio de sus competencias deben de abstenerse de adoptar decisiones o de realizar actos que perjudiquen o perturben el interés general y tengan, por el contrario, en cuenta la comunidad de intereses que las vincula entre sí que no puede resultar disgregada o menoscabada a consecuencia de una gestión insolidaria de los propios intereses. La autonomía -ha dicho la STC 4/1981- no se garantiza por la Constitución -como es obvio- para incidir de forma negativa sobre los intereses generales de la Nación o sobre intereses generales distintos de los de la propia entidad (FJ 10). El principio de solidaridad es su corolario (STC 25/1981, FJ 3)" (STC 64/1990, de 5 de abril - FJ 7º).

- El Estado tiene asignado el papel de "garantizar el principio de solidaridad (art. 138.1 CE), por lo que un Estatuto de Autonomía no puede contener criterios que desvirtúen o limiten dicha competencia estatal" (STC 31/2010, de 28 de junio FJ $131^{\circ}$ ). Esta iniciativa atribuida al Estado trae consigo dos consecuencias: a) Sin perjuicio de la legitimidad de los Estatutos de Autonomía para regular la Hacienda Autonómica, no son admisibles decisiones unilaterales de las CC.AA. que repercutan en el conjunto y condicionen las resoluciones de otras CC.AA. o de la propia Administración del Estado. b) Es el Estado el que en último término puede y debe tomar esas decisiones en las Cortes Generales, previo acuerdo adoptado en el órgano multilateral en que aquél ejercita funciones de cooperación y coordinación (Consejo de Política Fiscal y Financiera). ${ }^{163}$

Repárese en que este órgano colegiado está previsto en la LOFCA (art. 3) para, entre otros cometidos, aunar criterios de actuación en el ejercicio de su respectivo poder financiero por el Estado y las CC.AA., así como para evitar la toma de decisiones unilaterales por las CC.AA. que supongan una ruptura del sistema de financiación autonómica o que provoquen incoherencias injustificadas en su funcionamiento. De hecho, la STC 31/2010, de 28 de junio, vino a adherirse a la tesis de que la regulación sustancial del modelo de financiación autonómica debe plasmarse en la LOFCA y no en los estatutos de autonomía.

${ }^{163}$ Vid. STC 104/1988, de 8 de junio (FJ 4 ${ }^{\text {}}$; STC 289/2000, de 30 de noviembre (FJ 3º); y STC 14/2004, de 12 de febrero $\left(\mathrm{FJ}^{\circ}\right)$. 
En otras palabras, una norma estatutaria no es la vía jurídica apropiada para concretar el principio de solidaridad interterritorial, sino que lo procedente es que su configuración se realice a través de una ley estatal, como puede ser la LOFCA, previo consenso conseguido en el órgano representativo de las partes implicadas (Estado y CC.AA.), esto es, en el seno del Consejo de Política Fiscal y Financiera (VEGA GARCÍA, 2014, 247 y 265).

Parece pues que el Tribunal Constitucional le otorga al Estado un papel preponderante para mantener una comunidad de intereses convergentes entre las distintas Comunidades Autónomas, exigiendo de éstas un comportamiento leal en el ejercicio de su poder financiero. En esta línea, algunos autores consideran que aquellas disposiciones estatutarias que exigen inversiones especiales en la respectiva Comunidad Autónoma, aun cuando el Estatuto posea naturaleza jurídica de Ley Orgánica, no son asumibles por el Estado, al que no obligan. Para LAGO MONTERO (2008, 3018-3020) se trata de disposiciones inconstitucionales, en la medida en que sólo las Cortes Generales tienen la competencia de decidir las políticas inversoras que se acometen con cargo a los Presupuestos Generales del Estado. Por ello dicho autor concluye señalando que los Estatutos de Autonomía no son las normas adecuadas para dar cumplimiento al principio de solidaridad, incorporando reglas o mandatos dirigidos al Estado sobre la forma de nivelar los servicios y afrontar gastos de inversión.

Así las cosas, corresponde analizar a continuación los mecanismos regulados por la LOFCA y la Ley 22/2009 que, directa o indirectamente, han sido diseñados por el Estado para garantizar la solidaridad interregional y la igualdad en el acceso a los servicios públicos esenciales.

\subsection{Los instrumentos previstos en el ordenamiento estatal para hacer posible la solidaridad interterritorial}

La solidaridad, a pesar de su inicial apariencia como valor constitucional de difícil concreción o de su posible catalogación como concepto jurídico indeterminado, no es una regla retórica carente de valor jurídico vinculante. Muy al contrario, es un deber imperativo que demanda de los poderes públicos la búsqueda de fórmulas que lo hagan posible en términos prácticos y tangibles. 
Pues bien, entre los mecanismos previstos en la Constitución y la LOFCA para hacer efectiva la solidaridad en el actual sistema de financiación autonómica de régimen común cabe citar los siguientes: las asignaciones de nivelación; el Fondo de Suficiencia Global; el Fondo de Cooperación; el Fondo de Competitividad; y el Fondo de Compensación Interterritorial.

a) Las asignaciones de nivelación: el Fondo de Garantía de Servicios Públicos Fundamentales

Los distintos índices de riqueza entre territorios se traducen, ineludiblemente, en diferencias en la capacidad fiscal de los sujetos llamados a contribuir a las cargas públicas en cada una de esas demarcaciones territoriales. Por ello, la solidaridad demanda que se active una nivelación financiera, con arreglo a la cual, para evitar un mayor esfuerzo fiscal de los residentes en las Comunidades Autónomas menos desarrolladas, el Estado debe articular un mecanismo compensatorio que permita alcanzar un índice básico semejante en la prestación de los servicios públicos esenciales en el conjunto del territorio nacional.

Explicado de otra manera, se trata de que todas las Comunidades Autónomas, con independencia de la capacidad contributiva de sus ciudadanos, puedan prestar servicios públicos de calidad similar sin que para lograr ese objetivo sus residentes se vean abocados a asumir un esfuerzo fiscal superior.

De este modo, para dar cumplimiento a lo previsto en el art. 158.1 CE, el art. 15.1 de la LOFCA establece que el Estado garantizará en todo el territorio español la cobertura de un nivel mínimo de los servicios públicos fundamentales de su competencia, calificándose como tales la educación, la sanidad y los servicios sociales esenciales del Estado de bienestar (dependencia, discapacidad, protección del menor, personas en riesgo de exclusión social, etc.). Quiere ello decir que la nivelación no afecta a la totalidad de los servicios públicos prestados por las Comunidades Autónomas sino sólo a los anteriormente señalados, por lo que cada Comunidad Autónoma deberá asumir los restantes con sus propios medios, es decir, con su respectiva capacidad fiscal. Sería el caso, por ejemplo, de la justicia, la vivienda, la gestión en materia de protección del medio ambiente, etc. 
Es así que este mecanismo de nivelación pretende garantizar un rango básico de los servicios públicos esenciales, de tal manera que cada Comunidad reciba los mismos recursos por habitante, ajustados en función de sus necesidades diferenciales ${ }^{164}$. La redistribución de recursos y el reequilibrio económico entre territorios se consigue nutriendo el Fondo de Garantía de Servicios Públicos Fundamentales por dos vías: con un porcentaje de los tributos cedidos de las CC.AA. en términos normativos, es decir, cualquiera que sea el tipo de gravamen aplicado en sus impuestos cedidos, lo que es tanto como reconocer que el esfuerzo fiscal es muy similar entre las distintas Comunidades Autónomas (VEGA GARCÍA, 2014, 239); y con una aportación de recursos adicionales por el Estado con cargo a sus presupuestos, en los términos establecidos por el art. 9 de la Ley 22/2009.

Pese a las virtudes que, de entrada, se le podrían atribuir a ese Fondo de Garantía en aras de reforzar la solidaridad y la redistribución de la renta en un Estado descentralizado como el español, autores como LOZANO SERRANO (2016, 67-68) han detectado la existencia de incorrecciones o distorsiones en su configuración que ponen en duda su capacidad para cumplir los fines encomendados. En concreto, el citado autor menciona tres aspectos cuestionables. En primer lugar, no se tienen en cuenta las distintas condiciones de partida de los servicios prestados en cada territorio, por lo que, al haber disparidades iniciales, la financiación igual u homogénea que aporta el Fondo para nivelar no va a conseguir reequilibrar esas diferencias existentes de entrada. En segundo lugar, al no haber indicadores del nivel de prestación de partida de cada servicio no resulta posible procurar su igualación, ni siquiera conocer si tales servicios alcanzan la media nacional o si las asignaciones del Fondo lo mejoran. En tercer lugar, se aprecia una incorrección técnica en el art. 15.1 de la LOFCA, cuando este dispone que el Estado garantizará un nivel mínimo de los servicios públicos fundamentales "de su competencia”, para luego añadir que dichos servicios son los de educación, sanidad y los servicios sociales esenciales, es decir, los dos primeros transferidos a todas las CC.AA. y el tercero de competencia exclusiva de estas últimas en virtud de los estatutos de autonomía. Con esta defectuosa redacción la LOFCA se está apartando además del art.

\footnotetext{
${ }^{164}$ La STC 31/2010 ha querido subrayar que los derechos de los ciudadanos a recibir unos servicios básicos, con un nivel mínimo de calidad, no debe confundirse con el marco autonómico-territorial en que dichos servicios se prestan. En concreto, ha señalado que "ambas garantías tienen destinatarios diferentes, dado que la nivelación de los servicios fundamentales se proyecta sobre sus usuarios, mientras que la garantía de la solidaridad tiene como referencia a los distintos territorios autonómicos"
} 
158.1 CE, norma que se refiere a "los servicios y actividades estatales que hayan asumido" las Comunidades Autónomas, lo que a juicio de LOZANO SERRANO (2016, 68) "es una muestra palmaria del escaso rigor con que se regula un instrumento que no sólo sirve a la solidaridad y a la redistribución, sino a la garantía de unos derechos sociales básicos en el marco del Estado social y democrático de Derecho”.

Con todo, y sin perjuicio de que si fuese necesario se procediera a corregir los defectos o carencias apuntadas, las asignaciones de nivelación (Fondo de Garantía), al gozar de anclaje constitucional, constituyen un elemento clave del sistema de financiación autonómica presente y futuro para asegurar, en términos de justicia social, un equitativo acceso de los ciudadanos en condiciones mínimas de calidad a servicios públicos tan valiosos como la sanidad o la educación, cualquiera que sea la Comunidad Autónoma en la que residan. Por supuesto, esa pretendida convergencia interterritorial por medio de políticas de bienestar social no está reñida sino, todo lo contrario, debe compatibilizarse con otros instrumentos que incrementen con gastos de inversión las capacidades económicas y productivas de las Comunidades Autónomas menos desarrolladas.

b) El Fondo de Suficiencia Global

Se trata de una participación en los ingresos del Estado que pretende cubrir la diferencia entre las necesidades de gasto de cada Comunidad Autónoma y su capacidad tributaria más las transferencias del Fondo de Garantía (art. 13 LOFCA). El legislador ha calificado el Fondo de Suficiencia Global como "recurso de cierre del sistema", complementando los ingresos aportados por el Fondo de Garantía la capacidad fiscal de cada Comunidad (Preámbulo de la Ley 22/2009).

El problema es que el Fondo de Suficiencia no actúa en la práctica con la misma finalidad niveladora con la que teóricamente fue concebido el Fondo de Garantía, pues el Preámbulo de la Ley Orgánica 3/2009 reconoce que con aquél se pretende asegurar la financiación de competencias asumidas por las Comunidades Autónomas. Esta circunstancia lleva a LOZANO SERRANO $(2016,68)$ a señalar que se subvierte el objetivo de las asignaciones niveladoras, las cuales están llamadas a servir como instrumento financiero específico para la solidaridad y la redistribución, y no para sufragar el coste de los servicios de competencia autonómica. 
c) El Fondo de Competitividad y el Fondo de Cooperación

El primero de ellos ha sido creado con el fin de reforzar la equidad y la eficiencia en la financiación de las necesidades de los ciudadanos. También pretende reducir las diferencias en financiación homogénea per cápita entre Comunidades Autónomas, estimulando su autonomía y capacidad fiscal así como desincentivando la competencia fiscal a la baja. Es decir, el Fondo de Competitividad busca minorar o eliminar la competencia tributaria entre CC.AA. potenciando, por el contrario, a aquellas que consigan una mayor recaudación en uso de sus atribuciones normativas. La finalidad es loable pero incompleta en su configuración, ya que ignora los ratios de renta o riqueza de cada Comunidad, por lo que no todas tienen la misma situación de partida a la hora de ejercitar su poder tributario.

Por su parte, el Fondo de Cooperación, constituido con recursos adicionales del Estado, tiene como meta primordial equilibrar y armonizar el desarrollo regional estimulando el crecimiento de la riqueza y la convergencia regional en términos de renta ${ }^{165}$. Como vamos a ver a continuación, estos últimos objetivos coinciden claramente con los del Fondo de Compensación Interterritorial, lo cual denota que el legislador ha generado una duplicidad innecesaria con la creación del Fondo de Cooperación. Este último sería perfectamente suprimible siempre, claro está, que el Fondo de Compensación desempeñase el verdadero papel que le otorga el art.158.2 CE.

d) El Fondo de Compensación Interterritorial (FCI)

Nos encontramos ante un instrumento que, al amparo del art. 158.2 $\mathrm{CE}^{166}$, inicialmente nació vinculado al sistema de financiación autonómica, como lo prueba el hecho de que su regulación originaria se halla en el art. 16 de la LOFCA. A partir de los principios y reglas básicas establecidas en este precepto, se publicaron leyes posteriores que

\footnotetext{
165 Vid. arts. 23.1 y 24.1 de la Ley 22/2009, de 18 de diciembre, por el que se aprueba el Sistema de Financiación de las Comunidades Autónomas de Régimen Común y Ciudades con Estatuto de Autonomía. 166 Recordemos que dicho precepto dispone que, "con el fin de corregir desequilibrios económicos interterritoriales y hacer efectivo el principio de solidaridad, se constituirá un Fondo de Compensación con destino a gastos de inversión, cuyos recursos serán distribuidos por las Cortes Generales entre las Comunidades Autónomas y provincias, en su caso"
} 
abordaron con más detalle su contenido, finalidad y criterios de distribución ${ }^{167}$. La doctrina más destacada subrayó el importante papel que estaba llamado a desempeñar el FCI para asentar en España una estructura territorial sólida y equitativa sobre la base de la configuración político-administrativa de las Comunidades Autónomas (LOZANO SERRANO, 1984, 1749).

La conexión del FCI con la financiación de las CC.AA. determinó que, en un primer momento, se destinase a financiar inversión nueva de las competencias recibidas (por ejemplo, en materia de infraestructuras viarias), desligándose de los recursos para sufragar el coste efectivo de los servicios asumidos por aquéllas. Pero tampoco conviene soslayar la faceta intraterritorial -no sólo interterritorial- del FCI. Así, el Tribunal Constitucional tuvo ocasión de pronunciarse sobre ese y otros aspectos del FCI en diversas ocasiones (sentencias 63/1986; de 21 de mayo; 183/1988, de 13 de octubre y 250/1988, de 20 de diciembre). En concreto, la STC 183/1988 dejó sentado que "la Constitución española, al expresar el destino del FCI -y en general, los objetivos de la autonomía financiera de las CC.AA.- hace específica referencia, junto a la corrección de desequilibrios interterritoriales, a que debe «hacer efectivo el principio de solidaridad» (art. 158.2) en correspondencia con el establecimiento del «principio de solidaridad entre todos los españoles (art. 156.1 C.E.)» como inspirador de la autonomía financiera. El que las Cortes Generales, pues, en el desarrollo de las previsiones constitucionales y de la LOFCA, interpreten el principio de solidaridad en el reparto del FCI que ellas deben efectuar en el sentido de remediar también desequilibrios intraterritoriales, queda dentro de las facultades del legislador estatal, en virtud de la habilitación constitucional del art. 158.2: sin que resulte contradictoria con esa habilitación la obligación, establecida en el art. 2.2 LOFCA, de cada C.A. de «velar por su propio equilibrio territorial y por la realización interna del principio de solidaridad»; pues esta obligación no excluye la correlativa de los poderes públicos estatales" (FJ 5º).

De todos modos, con el paso del tiempo el FCI ha ido desvinculándose paulatinamente del núcleo central del modelo de financiación autonómica (UTRILLA DE LA HOZ, 2009, 98), perdiendo importancia en cuanto a su dotación económica ante el imparable avance de los fondos europeos de desarrollo regional (FEDER, FEOGA, FSE, etc.),

167 En la actualidad la Ley 22/2001, de 27 de diciembre, reguladora de los Fondos de Compensación Interterritorial 
muchos de los cuales también tuvieron como principales destinatarias a las regiones menos desarrolladas.

La prueba más evidente de que el FCI ha perdido interés como mecanismo de refuerzo de la solidaridad interterritorial está en que ni la Ley Orgánica 3/2009, de 18 de diciembre, de reforma de la LOFCA, ni la Ley 22/2009, de 18 de diciembre, se han ocupado de actualizarlo o al menos referenciarlo para reorientar su aplicación al nuevo modelo de financiación autonómica surgido de esas normas. La ineficiencia en su funcionamiento pasado justificaba sobradamente una regulación que lo adaptase a los nuevos tiempos, pero se prefirió crear un Fondo de Cooperación cuyos objetivos, como hemos avanzado, se solapan claramente con los del FCI. Todo ello sin descuidar que el art. 16.2 de la LOFCA también contempla adicionalmente la dotación anual en los Presupuestos Generales del Estado de un Fondo Complementario al FCI, con una cantidad equivalente a un tercio de este último. El Fondo Complementario se destina igualmente a gastos de inversión, aunque cabe la posibilidad de que, a solicitud de los territorios beneficiarios del mismo, se aplique a financiar gastos de funcionamiento asociados a inversiones sufragadas con cargo al FCI (art. 16.5 LOFCA).

En el plano de la docencia universitaria, y desde un punto de vista didáctico, al alumnado de Derecho financiero y tributario le resulta con frecuencia llamativo -y hasta difícil de comprender- cómo es posible que una las figuras clave creadas por la Constitución para potenciar la solidaridad interterritorial en la vertiente del gasto, el FCI, presente en la actualidad tal nivel de carencias y deficiencias cuando, por diversas razones, todavía persisten algunas desigualdades estructurales entre partes del territorio español. Es cierto que esas carencias se colman a veces, a través de los Presupuestos Generales del Estado, con importantes inversiones acometidas por los departamentos ministeriales con mayor capacidad de gasto, pero ello no debe suplantar ni ser a costa de subvertir la filosofía con la que fue creado por la Carta Magna el FCI.

En definitiva, resulta apremiante replantear los objetivos, criterios de reparto y análisis de resultados conseguidos con el FCI. No hay motivos sólidos que justifiquen la existencia de otros mecanismos niveladores que, como es el caso del citado Fondo de Cooperación, coinciden en buena medida por razón de sus fines con el FCI. Además, este último debe coordinarse con otros instrumentos implementados por la UE para corregir 
desequilibrios económicos interterritoriales, como ocurre en la actualidad con el impulso a la convergencia entre territorios europeos que, a través de medidas de muy diversa naturaleza, pretende conseguir el Instrumento Europeo de Recuperación («Next Generation EU»).

\subsection{Las distorsiones creadas en el sistema de financiación de los regímenes forales}

En ocasiones se ha querido equiparar el Estado autonómico con un verdadero Estado federal. Es posible que esa pretendida equivalencia sea real en el plano de las competencias político-administrativas, pues no cabe duda que las Comunidades Autónomas españolas son titulares de materias competenciales -en el plano normativo o ejecutivo- que no desmerecen en absoluto, e incluso en muchos casos superan, las que detentan otros entes políticos de Estados federales clásicos como Alemania, Australia, Suiza, Canadá, etc. Sin embargo, en el modelo español se producen ciertas asimetrías que rompen la homogeneidad que caracteriza a los entes territoriales de los Estados federales.

Una de ellas es lo que se ha dado en llamar los hechos diferenciales, es decir, un acervo exclusivo reconocido en el respectivo Estatuto de Autonomía, cuyas manifestaciones más notorias están constituidas por la lengua y cultura propias, un derecho civil especial, unas instituciones territoriales intermedias, etc. (OLIVER ARAÚJO, 2003, 208). Y a ese factor diferenciador habría que sumar otro que, a nuestro juicio, contribuye tanto o más que el primero a potenciar una asimetría o heterogeneidad impropias de un Estado federal, como sería la configuración de un poder financiero, destacadamente en materia tributaria, específicamente previsto para determinados territorios que conforman en España los regímenes forales de concierto o convenio.

La Carta Magna no oculta ambos elementos pues, respecto al primero, su preámbulo declara la voluntad de la Nación española de proteger a los pueblos de España "en el ejercicio de (...) sus culturas y tradiciones, lenguas e instituciones”. En relación al segundo, como es sabido, su Disposición Adicional 1" establece que "la Constitución ampara y respeta los derechos históricos de los territorios forales".

Centrándonos en este último, no faltan autores que defienden que el sistema de cupo propio de los regímenes forales es contrario a la solidaridad (HERNÁNDEZ LAVADO, 
2011, 477). Es cierto que, desde el punto de vista formal, la normativa de los territorios históricos es respetuosa con el principio de solidaridad. Prueba de ello es que el art. 2.Uno. $1^{\circ}$ de la Ley 12/2002, de 23 de mayo, por la que se aprueba el Concierto Económico con el País Vasco, dispone que el sistema tributario de los Territorios Históricos debe respetar la solidaridad "en los términos previstos en la Constitución y en el Estatuto de Autonomía”. A su vez, este último corrobora que el régimen de Concierto se aplicará de acuerdo con el principio de solidaridad a que se refieren los arts.138 y 156 de la Constitución [art. 41.1 f)]. En la misma línea, el Estatuto de Autonomía de Navarra proclama que la Comunidad Foral es solidaria con todos los pueblos de la nación española (art. 1). A mayor abundamiento, tanto en el País Vasco como en Navarra las partidas del FCI se incluyen dentro de las cargas financieras del Estado no asumidas por la respectiva Comunidad Autónoma.

Sin embargo, cuando se desciende del terreno formal al sustancial cabe observar que la realidad cambia, pues se constata que los recursos por habitante de los que disponen País Vasco y Navarra son superiores al resto de las CC.AA. y que, pese a ello, su contribución a la solidaridad ha sido menor que la de otras regiones con niveles de renta similares, en cierto modo debido a la compleja metodología seguida para calcular el "cupo" (VEGA GARCÍA, 2014, 228-229).

Hemos señalado en el apartado anterior de este trabajo que el Estado articula mecanismos de nivelación para compensar déficits de recursos por habitante en los servicios públicos esenciales de las CC.AA. que lo precisan, y sería lógico que las comunidades forales contribuyeran también a financiar esas transferencias dinerarias realizadas por la hacienda estatal. El Tribunal Constitucional ya advirtió que, con base en el art. 138.2 CE, "las limitaciones que el principio de solidaridad impone a la acción de todos los poderes públicos obligan a examinar con el mayor rigor aquellas medidas que, por su objeto inmediato, parecen dirigidas a asegurar a una parte del territorio beneficios o ventajas a expensas de otros" (STC 64/1990, de 5 de abril - FJ $8^{\circ}$ ).

Por ello, sin merma alguna del reconocimiento de los "derechos históricos" amparados por la Constitución, es preciso incorporar a las comunidades forales al régimen de solidaridad interterritorial que, con el mismo o mayor énfasis, también defiende la Carta Magna. Conjugar ambos criterios consagrados por la Constitución pasa por modificar la 
forma de cuantificar los servicios prestados por el Estado en País Vasco y Navarra, y por sumar a estos territorios a los instrumentos de compensación o nivelación que el Estado utiliza para prestar suficientes servicios públicos con un mínimo de calidad en todo el territorio nacional. De no corregirse esta situación, se estaría burlando el necesario equilibrio querido por la Carta Magna, la cual reconoce y garantiza en su art. 2 no sólo la autonomía de las nacionalidades y regiones que integran la Nación española, sino también "la solidaridad entre todas ellas".

\subsection{El contraste con la solidaridad federal en Alemania}

Frente a la asimetría que existe en España entre las CC.AA. de régimen común y las forales, en Alemania el principio de solidaridad en la financiación territorial se asienta en la idea de la igualdad formal y sustancial de los Länder. Además, la cooperación financiera entre las distintas estructuras territoriales y las fórmulas de compensación fiscal entre los Länder se han visto, si cabe, acrecentadas tras el proceso reunificación emprendido en 1990. Tampoco se ha cuestionado el hecho de que sea la legislación federal la que, previo consenso de los distintos territorios, configure el modelo de compensación financiera interterritorial.

Así, al margen de que en la República Federal existan transferencias complementarias del Bund a los territorios para garantizar la suficiencia financiera de estos, dos de los instrumentos que se han venido utilizando en Alemania para potenciar la solidaridad regional en la redistribución de recursos, y que se aparta por completo del modelo seguido en España, han sido la forma de asignar la recaudación del IVA entre los Länder y las transferencias financieras directas entre ellos (MARTÍNEZ EGAÑA, 2013, 28). El reparto de la recaudación del IVA entre los Länder se realiza en proporción al número de habitantes de cada Estado federado, aunque con la reserva de hasta una cuarta parte del total para aquellos con menor capacidad financiera. Por otro lado, la compensación horizontal de recursos entre los Länder tiene en cuenta distintas variables (mayores necesidades de financiación de algunos de ellos por sus características territoriales, baja densidad de población, capacidad financiera de los municipios, etc.). Con todo, este instrumento de compensación fue seriamente cuestionado por dos de los Länder donantes (Baviera y Hesse) ante el TC de Karlsruhe, con el objetivo de disminuir sus aportaciones que consideraban excesivas e injustificadas. 
Así las cosas, Alemania modificó sustancialmente su sistema de financiación a través de una reforma constitucional realizada en 2017, que entró en vigor el 1 de enero de 2020. Probablemente el cambio de mayor calado es el que trae causa del nuevo art. 107 de la Ley Fundamental de Bonn. En síntesis, dicha modificación comporta que los Länder donantes, que por mandato constitucional estaban obligados hasta entonces a transferir parte de sus ingresos, quedan liberados de tal carga financiera. Ahora bien, ello no significa que se haya dotado de mayor autonomía financiera a los Estados federados sino, todo lo contrario, se ha intensificado el poder financiero del Bund. En concreto, este último asume ahora el compromiso de aportar las subvenciones o transferencias financieras (verticales) a los Estados menos desarrollados -que antes afrontaban los Länder más prósperos (transferencias horizontales)-, pero con la contrapartida de que la Federación también acapara nuevas competencias inversoras en materia de educación e infraestructuras viarias, que antes eran de atribución exclusiva de los Estados federados. A su vez, se ha producido una recentralización de competencias fiscales que le permite a la Federación una mayor supervisión sobre la deuda y la política presupuestaria de todos los Länder, lo que en la práctica reduce el poder financiero de estos. Por su parte, los otrora Länder aportantes se ven beneficiados con esta nueva reordenación competencial y financiera por partida doble: dejan de asumir obligaciones de compensación con los Länder menos desarrollados y, además, la Federación pasa a invertir en sus territorios fondos destinados a mejorar la educación y las infraestructuras.

En suma, como señala VILLALBA CLEMENTE (2020, 58), con la reforma constitucional del sistema de financiación y solidaridad regional emprendida por Alemania en 2017 todas las partes salen ganando. Por un lado, los Länder más ricos, que hasta entonces cuestionaban el régimen de solidaridad aplicable con los Estados más necesitados, se ven liberados de parte de sus obligaciones compensatorias. Por otro lado, si bien es cierto que la reforma implica mayores desembolsos de recursos para la Federación, ésta consigue más competencias y un mayor control sobre la capacidad financiera de los Länder en materia de deuda y presupuestos.

Aunque los modelos de financiación de los entes regionales de España y Alemania no son equiparables en todos sus términos, habrá que observar con atención la evolución de 
la mencionada reforma alemana para extraer lecciones de interés que, en su caso, resulten aplicables en aras de reforzar la solidaridad interterritorial en nuestro país. Y, como señalábamos al comienzo de este trabajo, tales conclusiones o constataciones merecerán ser objeto de análisis y debate en las aulas universitarias en las que se cultiva el Derecho financiero y tributario.

En fin, las futuras generaciones de juristas deben ser conscientes de que los avances sociales del siglo XXI siguen construyéndose sobre valores ético-jurídicos que han sido y son el verdadero sustrato de la justicia y la igualdad, y uno de ellos es sin duda la solidaridad interterritorial.

\section{Bibliografía}

DOMÍNGUEZ ZORRERO, M.; SÁNCHEZ PINO, A. J. (2003). "La solidaridad interterritorial y la financiación autonómica”. Revista de Estudios Regionales, 66, 153165.

GONZÁLEZ-TREVIJANO, P. (2006). La España constitucional. Valencia: Tirant lo Blanch.

HERNÁNDEZ LAVADO, A. (2011). "La solidaridad interterritorial en la Constitución española de 1978”. En VV.AA., Del Derecho de la Hacienda Pública al Derecho Tributario. Estudios en honor a Andrea Amatucci. Vol. III. Bogotá - Napoli: Editorial Temis - Jovene Editore (463-492).

LAGO MONTERO, J. Ma (2008). "Las grietas del sistema de financiación autonómica: ¿hacia un confederalismo fiscal insolidario?”. En: M. Villar Ezcurra (Dir.), Estudios jurídicos en memoria de don César Albiñana García-Quintana. Vol. III. Madrid: Instituto de Estudios Fiscales (2985-3034).

LOZANO SERRANO, C. (1984). “Consideración jurídica del Fondo de Compensación Interterritorial”. En: VV.AA., Organización territorial del Estado: Comunidades Autónomas. Vol. III. Madrid: Instituto de Estudios Fiscales (1749-1770). 
LOZANO SERRANO, C. (2016). "La perversión de la garantía constitucional de derechos sociales por el sistema de financiación autonómica". Documentos - Instituto de Estudios Fiscales, 14, 59-69.

MARTÍNEZ EGAÑA, D. (2013). "La solidaridad interterritorial alemana". Documentos - Instituto de Estudios Fiscales, 10, 1-30.

OLIVER ARAUJO, J. (2003). La Constitución día a día. Valencia: Tirant lo Blanch.

OWENS, J.; LENNARD, M.; ANDRÉS AUCEJO, E. (2020). “La financiación del Desarrollo Sostenible: Tributación y Objetivos de Desarrollo Sostenible. Policy-making en Tributación, Cooperación tributaria Internacional y Gobernanza Fiscal Mundial como principal fuente de financiación de la Agenda 2030 de las Naciones Unidas". Revista de Educación y Derecho - Education and Law Review, 21, 1-16 (https://doi.org/10.1344/REYD2020.21.31339).

PÉREZ CALVO, A. (2005). “Algunos problemas serios en el Estado Autonómico”. En: Varios Autores, Constitución, Estado de las autonomías y justicia constitucional. (Libro homenaje al profesor Gumersindo Trujillo). Valencia: Tirant lo Blanch (1183-1200).

UTRILLA DE LA HOZ, A. (2009). "Fondos de desarrollo regional y solidaridad interterritorial”. Revista de Estudios Regionales, Vol. Extra. VIII, 97-128.

VEGA GARCÍA, A. (2014). "El principio constitucional de solidaridad interterritorial en España y en Alemania: aplicación y límites”. Revista d'Estudis Autonòmics i Federals, 20, 214-277.

VILLALBA CLEMENTE, F.G. (2020). "Sobre el sistema de financiación y compensación interterritorial alemán: especial referencia a su reforma constitucional de 2017”. Cuadernos Manuel Giménez Abad, 20, 43-61. 